\title{
Maintenance rehearsal affects knowing, not remembering; elaborative rehearsal affects remembering, not knowing
}

\author{
JOHN M. GARDINER, BERTHOLD GAWLIK, and ALAN RICHARDSON-KLAVEHN \\ City University, London, England
}

\begin{abstract}
In a directed-forgetting paradigm, each word in a study list was followed by a cue designating that word as either learn or forget. This cue appeared after either a short or a long delay. It was assumed that a long delay would increase maintenance rehearsal of all the words, and that only the words followed by a learn cue would be rehearsed elaboratively. Moreover, because the interval between the words was constant, a short cue delay should allow more time for elaborative rehearsal. In a subsequent test, subjects made remember or know responses to indicate whether recognition of each word was accompanied by conscious recollection or by feelings of familiarity in the absence of conscious recollection. The hypothesis was that remembering depends on elaborative rehearsal, and knowing depends on maintenance rehearsal. In accord with this hypothesis, the learn-versus-forget designation influenced remember but not know responses, and there were more remember responses after the short cue delay; cue delay influenced know responses, regardless of word designation.
\end{abstract}

In recognition memory, subjects experience at least two quite distinct states of awareness. Recognition is accompanied by either conscious recollection or feelings of familiarity in the absence of any recollective experience. These two states of awareness can be measured by remember and know responses (Tulving, 1985). A remember response indicates that subjects consciously recollect a test item's prior occurrence in an experiment. A know response indicates that subjects believe the test item did occur in the experiment, because it is familiar in the context, but they do not actually recollect its occurrence. Remember and know responses correspond with autonoetic and noetic consciousness, according to Tulving's (1983, $1985,1989,1993)$ theory, which proposes that these two kinds of awareness reflect retrieval from episodic and semantic memory systems, respectively.

Recent studies have revealed many functional dissociations between remember and know responses in recognition memory (for reviews see Gardiner \& Java, 1993a, 1993b). Variables that influence remembering, but not knowing, include shallow versus deep levels of processing (Gardiner, 1988), divided versus undivided attention (Gardiner \& Parkin, 1990), and studying under the in-

Correspondence should be addressed to J. M. Gardiner, Psychology Department, City University, Northampton Square, London EC1V OHB, England. fluence of the drug lorazepam versus a placebo (Curran, Gardiner, Java, \& Allen, 1993). It has been shown that other variables increase knowing and decrease remembering; these variables include studying nonwords versus words (Gardiner \& Java, 1990) and massed versus spaced repetition (Parkin \& Russo, 1993). Hitherto, only two variables have been shown to influence knowing and not remembering: preceding each word in a recognition test by a masked prime that is either a repetition of that word or an unrelated word (Rajaram, 1993), and same versus different study/test modalities (visual/auditory) following a highly perceptual orienting task (Gregg \& Gardiner, in press). In addition to these functional dissociations, the two subjective states of awareness have been shown to be differently related to various indices of brain function, including measures of frontal lobe function (Parkin \& Walter, 1992), event-related potentials (Smith, 1993), degree of sedation (Curran et al., 1993), and left versus right temporal lobe lesions (Blaxton, in press).

All this evidence rules out certain plausible but less interesting interpretations of the two subjective states of awareness, which are clearly governed by different psychological determinants and different aspects of brain function. They cannot be explained by invoking some simple unidimensional construct such as "trace strength." By the same token, they are not equivalent to levels of subjective confidence (see Gardiner \& Java, 1990; Parkin \& Walter, 1992; Rajaram, 1993). 
From the standpoint of Tulving's (1983, 1985, 1989, 1993) theory, the dissociations between remembering and knowing observed in recognition memory imply that both episodic and semantic memory systems contribute to overall recognition performance. In some instances, recognition is mediated by the episodic system and accompanied by autonoetic consciousness. In other instances, it is mediated by the semantic system and accompanied by noetic consciousness.

Remembering and knowing have also been interpreted by the transfer-appropriate-processing account of implicit and explicit memory performance advanced by Roediger and his associates (e.g., Roediger, 1990; Roediger \& McDermott, 1993; Roediger, Weldon, \& Challis, 1989). By this account, remembering is associated with conceptual processes and knowing is associated with perceptual processes (see, e.g., Blaxton, in press; Gardiner \& Java, 1990; Rajaram, 1993). Gardiner and Java (1993a, 1993b) argued that most of the available evidence fits reasonably well into a theoretical framework that combines this processing approach with the memory-systems theory, although there are increasing problems with this argument. For example, Rajaram and Coslett (1992) presented evidence that perceptual factors can influence remembering, but not knowing.

In two unpublished experiments, we found that another variable affecting remember, but not know, responses is having each word in the study list followed by a cue designating that word as either learn or forget. Subjects made far more remember responses for the words they were told to learn than for the words they were told to forget, but made a similar number of know responses. This directedforgetting paradigm was initially developed in connection with the distinction between maintenance and elaborative rehearsal (see, e.g., Bjork, 1972; Epstein, 1972; Woodward, Bjork, \& Jongeward, 1973; see also Craik \& Watkins, 1973; Geiselman \& Bjork, 1980). The general assumption-backed up by a great deal of evidence-is that in this procedure

It is not in the subject's interest to do more than hold the current word in memory until the cue appears. Associating or grouping the word with similar words presented earlier is counterproductive. Thus subjects engage in a rote, nonassociative rehearsal process, the function of which is to maintain the current word in short-term memory, and the consequences of which are quite different from those of constructive, associative rehearsal. (Woodward et al., 1973, pp. 615-616)

Among these consequences is that elaborative rehearsal benefits both free recall and recognition, but maintenance rehearsal benefits only recognition (Craik \& Watkins, 1973; Woodward et al., 1973). Geiselman and Bjork (1980) showed that maintenance rehearsal increased recognition in the auditory mode only if the speaker's voice at test was the same as the speaker's voice during rehearsal. They attributed the effect of maintenance rehearsal to familiarity judgments (in the general context) that depend on the perceptual match between the study and test items (see also Mandler, 1980; Woodward et al., 1973).
The purpose of the present research was not to elucidate the mechanisms underlying directed-forgetting effects (cf. Basden, Basden, \& Gargano, 1993; Bjork, 1989; MacLeod, 1989; Paller, 1990), but to use the paradigm to vary the amount of maintenance and elaborative rehearsal. The crucial manipulation, aside from word designation (learn vs. forget), was the delay between the presentation of each word and the appearance of the cue. Following earlier research on the effects of cue delay (e.g., Wetzel \& Hunt, 1977; Woodward et al., 1973), the assumption was that increasing the interval between each word and its cue would prolong the period of maintenance rehearsal and, if the total presentation time was constant, correspondingly reduce the opportunity for elaborative rehearsal.

Our hypothesis was that one factor that influences remembering and knowing is type of rehearsal; that is, remember responses depend on elaborative rehearsal and know responses depend on maintenance rehearsal. Thus, we predicted that word designation would have a large effect on remember responses but no effect on know responses (replicating the results of our previously mentioned unpublished experiments) and that know responses would increase with longer cue delay, because the delay prolongs the period of maintenance rehearsal and it is assumed that this rehearsal influences familiarity (Geiselman \& Bjork, 1980; Mandler, 1980). Finally, with a short cue delay, subjects should be able to devote more time, after the cue, to elaborative rehearsal of the to-be-learned words, and this should additionally boost the number of remember responses.

\section{METHOD}

\section{Subjects}

The subjects were 32 undergraduate students at City University, London. They were tested individually and were paid for their participation.

\section{Design and Materials}

The experiment involved a $2 \times 2$ design in which the factors were word designation (to be learned vs. to be forgotten) and cue delay (short vs. long). Both factors were varied within subjects. The materials were 168 words taken from those used by Tulving, Schacter, and Stark (1982). Eight of these words served as nontested buffer items. The remaining 160 words were randomly divided into two sets of 80 words each. Each of these two sets of 80 words was used to provide study lists for half of the subjects and distractors for the other half. Each study list of 80 words was further divided at random into two sublists, one for the short cue delay condition and one for the long cue delay condition. Cue delay condition was blocked; half of the subjects received the short-delay condition first, and half received the long-delay condition first. Within each cue delay condition, half of the words were designated as to-belearned words and half were designated as to-be-forgotten words. These conditions were further counterbalanced with respect to cue delay order. In sum, all the words were fully rotated across all conditions: targets versus distractors, short versus long cue delay, the order in which cue delay was blocked, and learn versus forget.

\section{Procedure}

The study lists were presented on an Apple SE 1/20 computer. Each subject studied 40 words in the short cue delay condition and 40 words in the long cue delay condition. Before each set of these 40 words was presented, 4 buffer words were presented ( 2 learn, 2 forget) in order to accustom the subjects to the appropriate cue delay. These words remained constant. Each study list word appeared on the screen for $1 \mathrm{sec}$. In the short-delay condition, the cue appeared directly $(0 \mathrm{sec})$ after the 
study list word and remained on the screen for $1 \mathrm{sec}$. There was a 5 -sec interval before the next word appeared. In the long-delay condition, the 5 -sec interval directly followed the study list word and the cue appeared (for $1 \mathrm{sec}$ ) at the end of this interval. Hence, the total presentation time remained the same (7 sec/word), regardless of cue delay. The cue for a to-be-learned word was "LLLL"; the cue for a to-be-forgotten word was "FFFF." The order of word presentation within each block of the study list was randomized separately for each subject.

After a 1-day retention interval, the subjects returned to the laboratory for the recognition test. This test consisted of all 160 critical words mixed together in a single random order, typed onto two sheets of paper with four columns of 20 words per sheet. The subjects were told to work carefully down each column in turn and to circle the words they recognized from the study list. They were told not to guess. In addition, the subjects were told that they were to write an " $R$ " next to each word they recognized if recognizing the word was accompanied by some conscious recollection of the word's occurrence in the study list, and a " $K$ " if recognizing the word was accompanied by a feeling of knowing that the word had occurred in the study list without any recollection of its occurrence. The subjects were given detailed instructions that were similar to those that have been used in previous studies (see, e.g., Gardiner, 1988; Gardiner \& Java, 1990; Gardiner \& Parkin, 1990; Rajaram, 1993). One subject, who clearly failed to understand these instructions, was replaced.

\section{RESULTS AND DISCUSSION}

The main results are summarized in Table 1; they generally confirmed our predictions. Recall that we expected the know responses to be influenced only by cue delay. On the hypothesis that knowing depends on maintenance rehearsal, a long cue delay was expected to increase the know responses for both the learn and forget words. On the hypothesis that remembering depends on elaborative rehearsal, the remember responses were expected to be influenced by both word designation and cue delay. Only the learn words should be rehearsed elaboratively, so there should be more remember responses for the learn than for the forget words. Moreover, there was more opportunity for elaborative rehearsal with a short cue delay, so it was expected that the remember responses for the learn words would receive an additional boost in this condition. It is also of interest to note how this account explains the null effect of cue delay on the overall recognition of learn words, a result that closely replicates previous findings by Wetzel and Hunt (1977, p. 242, Figure 4), by showing how the two types of rehearsal offset each other.

Statistical analyses of the data summarized in Table 1 are consistent with our conclusions $(\alpha=.05)$. An analysis of variance (ANOVA) on the overall scores showed a significant effect of word designation $[F(1,31)=42.67$,

Table 1

Proportion of Responses for Each State of Awareness as a Function of Cue Delay in Directed Forgetting

\begin{tabular}{|c|c|c|c|c|c|}
\hline \multirow{3}{*}{$\begin{array}{l}\text { Response } \\
\text { Proportion }\end{array}$} & \multicolumn{4}{|c|}{ Delay } & \multirow[b]{3}{*}{ Unstudied } \\
\hline & \multicolumn{2}{|c|}{ Short } & \multicolumn{2}{|c|}{ Long } & \\
\hline & Learn & Forget & Learn & Forget & \\
\hline Remembering & .50 & .23 & .40 & .26 & .03 \\
\hline Knowing & .18 & .20 & .27 & .29 & .10 \\
\hline Overall & .68 & .43 & .67 & .55 & .13 \\
\hline
\end{tabular}

$\left.M S_{\mathrm{e}}=.03\right]$ and a significant interaction between word designation and cue delay $\left[F(1,32)=7.47, M S_{\mathrm{e}}=.02\right]$. The main effect of cue delay was also significant $[F(1,31)=$ $\left.7.47, M S_{\mathrm{e}}=.01\right]$. Separate ANOVAs were carried out on the remember and know responses. For the remember responses, there was a significant effect of word designation $\left[F(1,31)=42.09, M S_{\mathrm{e}}=.03\right]$ and a significant interaction between word designation and cue delay $\left[F(1,31)=9.08, M S_{\mathrm{e}}=.02\right]$. The main effect of cue delay was not quite significant $\left[F(1,31)=3.79, M S_{\mathrm{e}}=\right.$ $.01, p=.058]$. For the know responses, the main effect of cue delay was significant $\left[F(1,31)=19.19, M S_{\mathrm{e}}=\right.$ $.01]$, but neither the main effect of word designation nor the interaction was significant ( $F<1$ in each case).

Evidence that remembering is influenced by elaborative rehearsal complements previous evidence that this state of awareness reflects an episodic memory system that depends heavily, though not exclusively, on conceptual processing. Evidence that knowing is influenced by maintenance rehearsal suggests that, although maintenance rehearsal is sufficient for an item's occurrence to change the semantic memory system, it is not sufficient enough for an item's occurrence to change the episodic system. This suggestion follows from the idea that the episodic system is defined by remembering, not by the mere occurrence of events; events are also recorded in the semantic system (see Tulving, 1993; Tulving, Hayman, \& MacDonald, 1991).

The effect of maintenance rehearsal on know responses provides good support for interpreting this effect in terms of familiarity (Geiselman \& Bjork, 1980) and for Mandler's $(1980,1989)$ theory in particular. In Mandler's theory, elaboration, which involves associative interitem relations, is distinguished from integration (or activation), which involves the strengthening of intraitem features. Our results support the theory because it assumes that conscious recollection depends on elaboration and that integration gives rise to increased feelings of familiarity. On the other hand, contrary to what the theory also predicts, there is little or no evidence that maintenance rehearsal increases perceptual priming (Greene, 1986; RichardsonKlavehn \& Bjork, 1988).

It is possible that some of the other variables that influence knowing and remembering might do so indirectly by affecting the type of rehearsal that subjects employ. For example, nonwords, compared with words, might give rise to more know responses and fewer remember responses (Gardiner \& Java, 1990) because nonwords lead to more maintenance rehearsal and less elaborative rehearsal. Massed, compared with spaced, repetition might be associated with more know and fewer remember responses for much the same reason (Parkin \& Russo, 1993).

Finally, from a broader theoretical perspective, the results from our approach converge nicely with those from other approaches (e.g., Jacoby, 1991; Mandler, 1980) in the conclusion that recognition memory has at least two quite distinct bases, each involving a different state of awareness. In particular, the finding that maintenance 
rehearsal increases know responses without influencing remember responses opens up fresh possibilities for gaining a better understanding of familiarity-based recognition memory.

\section{REFERENCES}

Basden, B. H., Basden, D. R., \& Gargano, G. J. (1993). Directed forgetting in implicit and explicit memory tests: A comparison of methods. Joumal of Experimental Psychology: Learning, Memory, \& Cognition, 19, 603-616.

BJork, R. A. (1972). Theoretical implications of directed forgetting. In A. W. Melton \& E. Martin (Eds.), Coding processes in human memory (pp. 217-235). Washington, DC: Winston.

Bjork, R. A. (1989). Retrieval inhibition as an adaptive mechanism in human memory. In H. L. Roediger III \& F. I. M. Craik (Eds.), Varieties of memory and consciousness: Essays in honour of Endel Tulving (pp. 309-330). Hillsdale, NJ: Erlbaum.

BLAXTON, T. A. (in press). The role of temporal lobes in recognizing nonverbal materials: Remembering versus knowing. Neuropsychologia.

Craik, F. I. M., \& Watkins, M. J. (1973). The role of rehearsal in short-term memory. Journal of Verbal Learning \& Verbal Behavior, 12, 599-607.

Curran, H. V., Gardiner, J. M., Java, R. I. Allen, D. (1993). Effects of lorazepam upon recollective experience in recognition memory. Psychopharmacology, 110, 374-378.

EPSTEIN, W. (1972). Mechanisms of directed forgetting. In G. H. Bower (Ed.), The psychology of learning and motivation (Vol. 6, pp. 147191). New York: Academic Press.

GARDiner, J. M. (1988). Functional aspects of recollective experience. Memory \& Cognition, 16, 309-313.

GARDINER, J. M., \& JAVA, R. I. (1990). Recollective experience in word and nonword recognition. Memory \& Cognition, 18, 23-30.

GaRDiner, J. M., \& JAVA, R. I. (1993a). Recognition memory and awareness: An experiential approach. European Journal of Cognitive Psychology, 5, 337-346.

Gardiner, J. M., \& JAVA, R. I. (1993b). Recognizing and remembering. In A. F. Collins, S. E. Gathercole, M. A. Conway, \& P. E Morris (Eds.), Theories of memory (pp. 163-188). Hillsdale, NJ: Erlbaum.

Gardiner, J. M., \& Parkin, A. J. (1990). Attention and recollective experience in recognition memory. Memory \& Cognition, 18, 579-583.

Geiselman, R. E., \& BJork, R. A. (1980). Primary versus secondary rehearsal in imagined voices: Differential effects on recognition. Cognitive Psychology, 12, 188-205.

GREENE, R. L. (1986). Word stems as cues in recall and completion tasks. Quarterly Journal of Experimental Psychology, 38A, 663-673.

GregG, V. H., \& GardINer, J. M. (in press). Recognition memory and awareness: A large cross-modal effect on "know" but not "remember" responses following a highly perceptual orienting task. European Journal of Cognitive Psychology.

JACOBY, L. L. (1991). A process dissociation framework: Separating automatic from intentional uses of memory. Journal of Memory \& Language, 30, 513-541.

MACLEOD, C. M. (1989). Directed forgetting affects both direct and indirect tests of memory. Joumal of Experimental Psychology: Learning. Memory, \& Cognition, 15, 398-406.

MandleR, G. (1980). Recognizing: The judgment of previous occurrence. Psychological Review, 87, 252-271.
Mandler, G. (1989). Memory: Conscious and unconscious. In P. R. Solomon, G. R. Goethals, C. M. Kelley, \& B. R. Stephens (Eds.), Memory: Interdisciplinary approaches (pp. 84-106). New York: Springer-Verlag.

PALLER, K. A. (1990). Recall and stem-completion priming have different electrophysiological correlates and are modified differently by directed forgetting. Joumal of Experimental Psychology: Leaming, Memory, \& Cognition, 16, 1021-1032.

PARKIN, A. J., Russo, R. (1993). On the origin of functional differences in recollective experience Memory, 1, 231-237.

Parkin, A. J., W Whter, B. M. (1992). Recollective experience, aging, and frontal dysfunction. Psychology \& Aging, 7, 290-298.

RAJARAM, S. (1993). Remembering and knowing: Two means of access to the personal past. Memory \& Cognition, 21, 89-102.

Rajaram, S., \& Coslett, H. B. (1992, November). Funther dissociations between "remember" and "know" responses in recognition memory. Paper presented at the meeting of the Psychonomic Society, St. Louis, MO

Richardson-Klavehn, A., \& Bjork, R. A. (1988). Primary versus secondary rehearsal in an imagined voice: Differential effects on recognition memory and perceptual identification. Bulletin of the Psychonomic Society, 26, 187-190.

RoEDiger, H. L., III (1990). Implicit memory: Retention without remembering. American Psychologist, 45, 1043-1056.

Roediger, H. L., III, \& MCDermotT, K. B. (1993). Implicit memory in normai human subjects. In J. Grafman \& F. Boller (Eds.), Handbook of neuropsychology (Vol. 8, pp. 63-131). Amsterdarn: Elsevier

Roediger, H. L., II, Weldon, M. S., \& Challis, B. H. (1989). Explaining dissociations between implicit and explicit measures of retention: A processing account. In H. L. Roediger III \& F. I. M. Craik (Eds.), Varieties of memory and consciousness: Essays in honour of Endel Tulving (pp. 3-41). Hillsdale, NJ: Erlbaum.

SмIтн, M. E. (1993). Neuropsychological manifestations of recollective experience during recognition memory judgments. Journal of Cognitive Neuroscience, $5,1-13$.

Tulving, E. (1983). Elements of episodic memory. New York: Oxford University Press.

Tulving, E. (1985). Memory and consciousness. Canadian Psychologist, 26, 1-12

Tulving, E. (1989). Memory: Performance, knowledge, and experience. European Journal of Cognitive Psychology, 1, 3-26.

Tulving, E. (1993). What is episodic memory? Current Directions in Psychological Science, 2, 67-70.

Tulving, E. Hayman, C. A. G., \& MacDonald, C. A. (1991), Long lasting perceptual priming and semantic learning in amnesia: A case study. Joumal of Experimental Psychology: Learning, Memory, \& Cognition, 17, 595-617.

Tulving, E., Schacter, D. L., \& Stark, H. A. (1982). Priming effects in word-fragment completion are independent of recognition memory. Journal of Experimental Psychology: Learning, Memory, \& Cognition, 8, 336-342.

Wetzel, C. D., Hunt, R. E. (1977). Cue delay and the role of rehearsal in directed forgetting. Journal of Experimental Psychology: Human Learning \& Memory, 3, 233-245.

WoOdward, A. E., BJoRK, R. A., \& JoNGEWARD, R. H. (1973). Recall and recognition as a function of primary rehearsal. Joumal of Verbal Learning \& Verbal Behavior, 12, 608-617.

(Manuscript received May 11, 1993; revision accepted for publication June $30,1993$. 